\title{
Study on Optimization of Architectural Shape Based on Wind Environment: A Study in Taiyuan, China
}

\author{
Yumeng Shi ${ }^{1}$, Ming $\mathrm{Lu}^{1, *}$, Weijian $\mathrm{Li}^{2}$ \\ ${ }^{1}$ School of Architecture, Harbin Institute of Technology, China \\ ${ }^{2}$ Department of Computer Science University of North Carolina at Chapel Hill, USA
}

Copyright $(\mathcal{C} 2015$ by authors, all rights reserved. Authors agree that this article remains permanently open access under the terms of the Creative Commons Attribution License 4.0 International License

\begin{abstract}
Wind environment and architectural shape share a close relationship. During the formation of building shape, it is rather necessary to optimize it with analysis on wind environment. Based on STAR CCM + software platform, and with a project in Taiyuan as example, this article focuses on how to optimize architectural shape based on wind environment step by step. From an information point of view, this article aims to fill the blank in architectural design caused by deficiency of environmental consideration in 'subjective modeling'.
\end{abstract}

Keywords Architectural Shape, Wind Environment, Shape Formation, Optimization

\section{Introduction}

Currently, the concept of sustainable development has been widely applied within China. Every designing aspect, including shape arrangement, outdoor environment, environmental friendly material and environmental friendly utility, needs to contain the concept of sustainable development of architecture. Properly designed building shape can improve the efficiency of the building itself, which is the main method for a building to achieve 'active energy saving'; additionally, it is also able to adjust the outdoor micro-climate, and create a delightful outdoor environment.

Wind environment and architectural shape share a close relationship, in a way that both building blocks and façade shape will affect the direction and intensity of wind, which relates to the building's ability of autonomous energy saving and micro-climate adjusting[1]. Therefore, during the design of architectural shape, we need to optimize the design based on wind environment, in order to fulfill the double purposes of green building and outdoor micro-climate.

Thus, this paper focused on how to optimize architectural shape during building production based on wind environment. Case study of Taiyuan was selected due to its location in suburb and there was no interference from buildings and urban. Also, software simulation and comparative analysis were conducted to instruct optimization of the architecture shape.

\section{Literature Review}

Wind fields formed by buildings affect people's livings in many ways. Improper wind field will affect people's comfort outside the building, or might even threaten a person's life. In 1972, an old man in Portsmouth was stroked by strong wind when passed the corner of a skyscraper and fell to the ground. At last, he died of skull fracture. In addition, improper design of building shape and unreasonable arrangement of building blocks, hinder buildings from getting fresh air, aggravate the reproducing of harmful bacteria and virus, and threaten residents' health [2]. The outbreak of SARS is an example. Thus, benevolent wind environment surround buildings can ameliorate air quality, and offer health to both buildings and people. More important, the flow stagnancy also influences the buildings and urban, causing urban problems such as heat island effect and resource shortage.

Currently in China, the methods utilizing wind environment to optimize the building through local climate such as overhead ground floors, layout buildings group, urban design and other aspects has matured. Jing Wang in her research "Research on Building Layout Strategy in Riverfront of Shenzhen on Wind environment" explores building layout strategies of urban waterfront neighborhoods from two levels: city wind strategies and guide wind strategies while explores strategies uses of waterfront neighborhoods in Shenzhen[3]. The article aims to propose a design method, which considered wind environment in each design step.

\section{Methodology}

The investigation consists of site selection and simulated 
data. Through the combination to the actual project design, we studied how to optimize architectural shape in the design process based on wind environment.

\subsection{Selected Site Description}

The project is located in Taiyuan, Shanxi Province. The project site is located on 6.6 square meters, which will include scientific, offices and related service facility. Sustainable, environmentally sound features of the building will be highlighted in the design, as well as the application of green building technologies such as energy efficient construction, a district-wide central heating system and vertical greening.

\subsection{Data Resource}

The project aims to optimize the plan according to the local climate during the design, which helps building gain nature ventilation and energy efficiency. Therefore, the local meteorological parameters are pretty valued in the optimization.

The wind direction in Taiyuan is affected by southeast monsoon. The prevailing wind is northwest wind in winter, and west wind in summer. According to data from Meteorological Data Set for Building Thermal Environment of China, we take the average of typical meteorological data in Taiyuan (Table 1), based on which we build the parameter base of wind environment optimization. After designing the basic building mass according to the design idea, we use STAR CCM+ to simulate, analyze and optimize the building shape in different monsoon environment.

Table 1. Meteorological Parameters under Wind Environment Simulation

\begin{tabular}{|c|c|c|}
\hline Season & $\begin{array}{c}\text { Prevailing } \\
\text { Wind }\end{array}$ & $\begin{array}{c}\text { Average Wind } \\
\text { Speed on 10 meters } \\
\text { level } / \mathbf{m} \cdot \mathbf{s}^{-\mathbf{1}}\end{array}$ \\
\hline Summer & West Wind & 2.1 \\
\hline Winter & $\begin{array}{c}\text { North By } \\
\text { Northwest Wind }\end{array}$ & 2.6 \\
\hline
\end{tabular}

\subsection{Data Process}

After obtaining the basis meteorological data, we used $\mathrm{CAD}$ to model and STAR CCM+ to simulate, analyzed and optimized the building shape. We got vector and scalar diagram, which stand for wind speed and wind pressure of the building, and then we used wind speed and wind pressure standards respectively to optimize.
Wind speed standard: According to a research, when the $1.5 \mathrm{~m}$-wave-height wind speed is between $1 \mathrm{~m} / \mathrm{s}$ and $5 \mathrm{~m} / \mathrm{s}$ in summer, $0.6 \mathrm{~m} / \mathrm{s}$ and $5 \mathrm{~m} / \mathrm{s}$ in transitive seasons and below $3 \mathrm{~m} / \mathrm{s}$ in winter, the wind will offer the most comfortable feeling respectively [4]. Besides, the ratio of outdoor comfortable wind zone is another standard for optimization.

Wind pressure standard: The pressure discrepancy between a building's windward side and leeward side is a critical index to evaluate whether this building can be ventilated or not. When the pressure discrepancy is between $1.5 \mathrm{~Pa}$ and $5 \mathrm{~Pa}$, this building can realize natural ventilation in summer and heat preservation in winter.

Therefore, when considering building's shape based on wind environment, we need to first consider the $1.5 \mathrm{~m}$-wave-height wind field created by building blocks by evaluating and optimizing the building's shape according to residents' comfort degree; and second consider whether the building surface can generate proper wind pressure in different seasons. This way, we can realize our general optimization idea.

\section{Methods of Optimizing Architectural Shape Based on Wind Environment}

\subsection{Optimizing Building Mass}

After making the basic building mass plan, we should first optimize the building shape near the ground layer. The standard for this optimization is the $1.5 \mathrm{~m}$-wave-height wind speed above the people activity area. Properly controlled wind environment around the buildings will not only offer pedestrians comfortable living experience, but also prevent hazard gas stagnancy from happening.

The initial plan for building mass are three paralleled-placed cuboids (figure 1). The software simulation reveals that there is a wide range of clam air area, together with the occurrence of vortex near the ends of them. That's why we need to optimize this design by adding two opposite square mild slopes, which act as buffering and introducing area for winds. As shown in figure 1, the airflow through the structure is optimized. After the first optimization, we can see the vortex has been radically weakened, so that the wind field has been distributed evenly around the buildings. Furthermore, we need to use apparent wind speed to examine this design, so that the buildings can generate a delightful outdoor wind environment. 


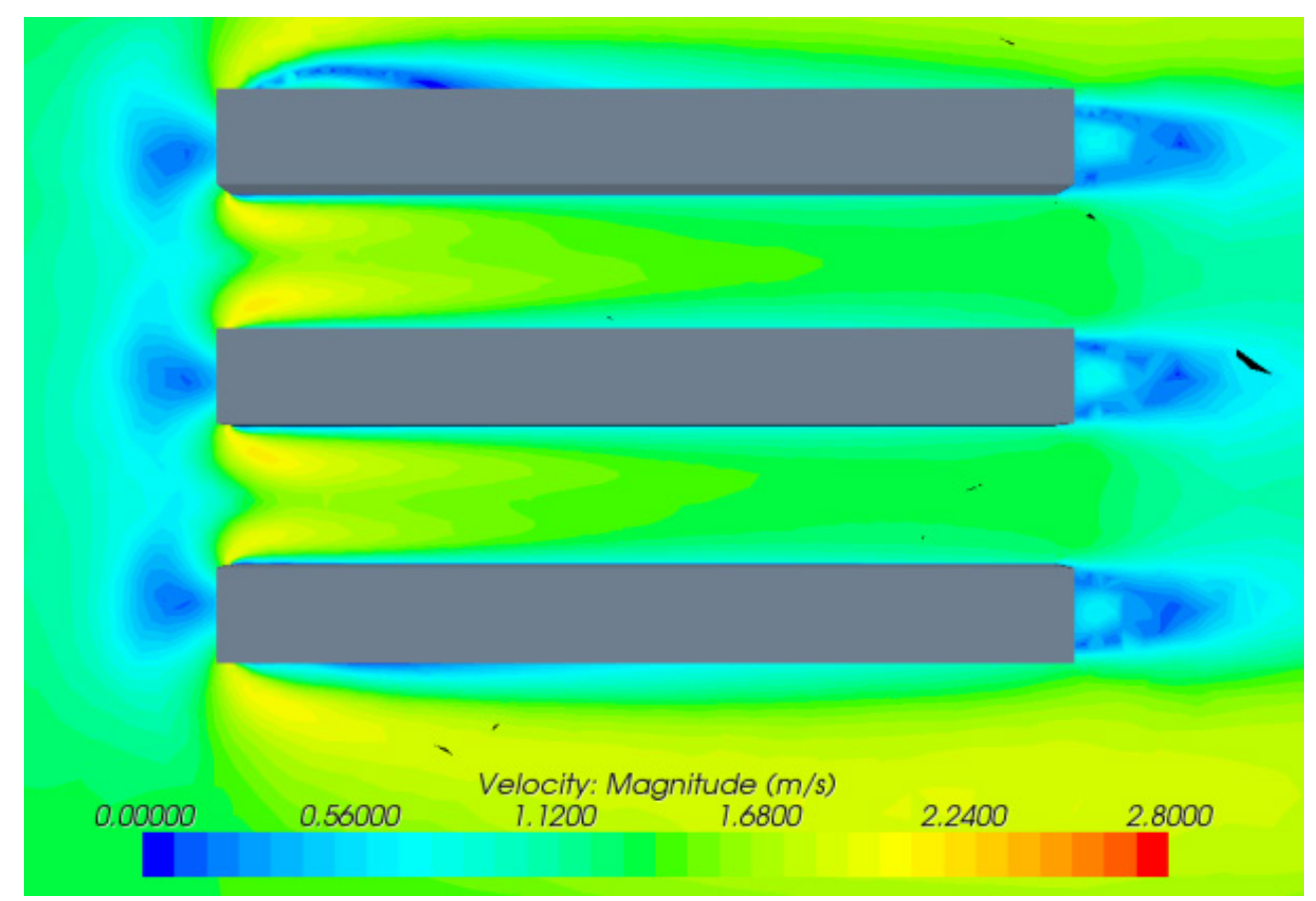

(a) Before Optimization

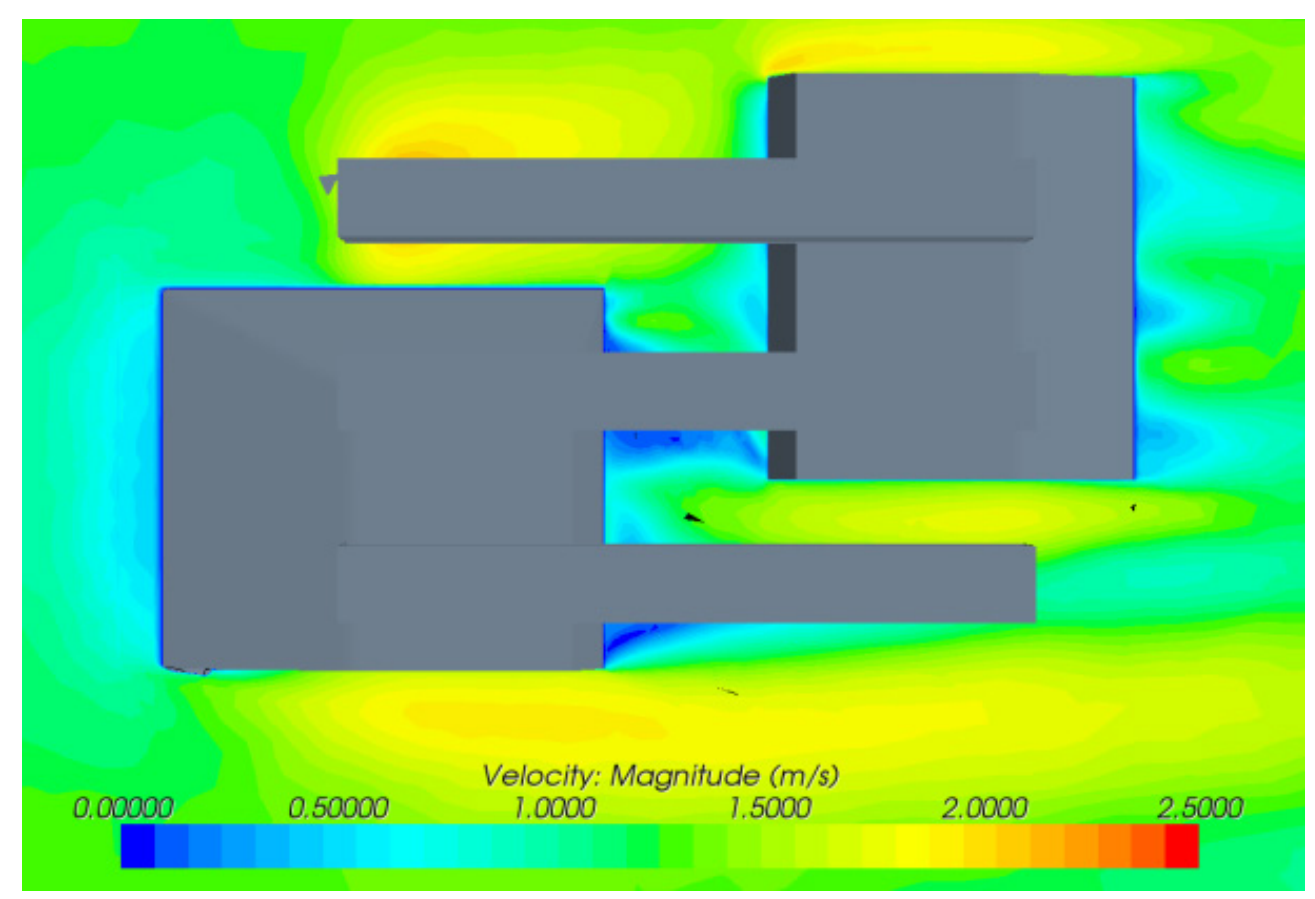

(b) After Optimization

Figure 1. Optimized Wind Scalar Diagram

Typically, international wind scale is defined under Beaufort wind scale. According to Beaufort wind scale (Table 2), if $1.5 \mathrm{~m}$-wave-height wind speed is under $0.1 \mathrm{~m} / \mathrm{s}$, people will feel oppressed and unwell. Back to the plan, we can notice that the wind speed near the intersection between squares and rectangles is too low, which might trigger discomfort for pedestrians. Thus, we optimize the design for the second time, by rotating the rectangle mass. The software simulation is as followed. 
Table 2. Beaufort Wind Scale

\begin{tabular}{|c|c|c|c|}
\hline Description & $1.5 \mathrm{~m}$-wave-height Wind Speed $(\mathrm{m} / \mathrm{s})$ & Effects Observed on Land & Effects on Pedestrians \\
\hline Calm & $0.0-0.1$ & Calm. Smoke rises vertically. & No feeling. Oppressed. \\
\hline Light Air & $0.1-1.0$ & Smoke drift indicates wind direction. & Hard to feel. \\
\hline Light Breeze & $1.0-2.1$ & Wind felt on exposed skin. & Wind felt on face. \\
\hline Gentle Breeze & $2.1-3.4$ & Light flags extended. & Hair blowing in the wind. \\
\hline Moderate Breeze & $3.4-5.0$ & Dust and loose paper raised. & Dust raised and hair blown. \\
\hline Fresh Breeze & $5.0-6.7$ & Small trees in leaf begin to sway. & $\begin{array}{c}\text { Wind is strong enough. Limit of } \\
\text { land wind. }\end{array}$ \\
\hline
\end{tabular}

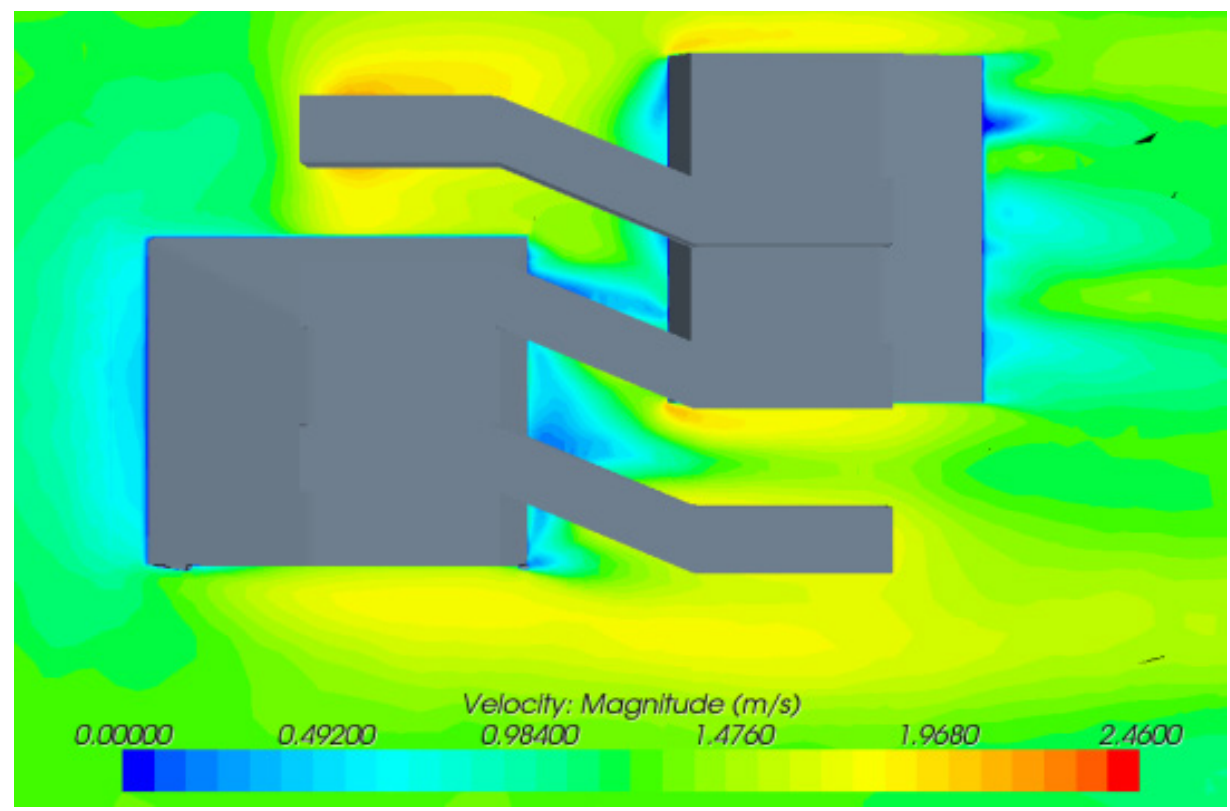

Figure 2. Wind Scale Diagram after Rotating Blocks

After rotating the mass, we illustrate the optimized design in Figure 2. It is not hard to notice that this new design ameliorate wind field by reducing the range of low-wind-speed area. Additionally, the wind speeds near the field between rectangles and squares are basically around $0.3-0.9 \mathrm{~m} / \mathrm{s}$, which is light air, hard for pedestrians to feel, and suits for static activity. Thus, we can assure that this design for mass is feasible.

\subsection{Building Form Optimization}

\subsubsection{High Altitude Layer Optimization}

After determining basic location of building mass, we begin to optimize the building form. During this procedure, the main goal of optimization is to help the building to gain natural ventilation. The high-altitude wind speed will affect building wind pressure on difference. According to a research, natural ventilation will take place when the pressure difference between the building windward and leeward wall increases over 1.5 Pa. Therefore, we choose the $10 \mathrm{~m}$-wave-height wind speed as optimization parameter. If the horizontal average wind speed at $10 \mathrm{~m}$-height altitude is less than $1.3 \mathrm{~m} / \mathrm{s}$, the pressure difference between building windward and leeward wall will be less than $2 \mathrm{~Pa}$, which is unfavorable for natural ventilation in summer. However, in winter, the horizontal average wind speed at 10m-height altitude is more than $2.2 \mathrm{~m} / \mathrm{s}$, and the pressure difference between building windward and leeward wall is more than 5 $\mathrm{Pa}$, which radically increases the volume of infiltrated cold wind and unfavorable for heat preservation[4]. Thus, the strategy for this optimization is to optimize the building shape based on wind speed at 10m-height altitude. Furthermore, software simulation will give the result of pressure distribution in different seasons, based on which final plan can realize natural ventilation and heat preservation.

First, we do the simulation for wind environment at 10 -meter altitude, and find that the wind speeds between the rectangles are between $2.4 \mathrm{~m} / \mathrm{s}$ and $2.7 \mathrm{~m} / \mathrm{s}$. As a result, Valley Effect takes places, which is unfavorable for heat preservation in winter; wind speed is too slow at southeastern corner, which is unfavorable for natural ventilation in summer. Therefore, further optimization on building shape is necessary. We add more rectangles so that they can intersect with each other, creating a zigzag form. After the second software simulation, we find that the optimized shapes evenly distribute the former over-slow wind and over-fast wind, so that the general intensity of the wind field is moderate. The general wind speed is between $1.6 \mathrm{~m} / \mathrm{s}$ and $2.3 \mathrm{~m} / \mathrm{s}$, which fulfill the requirement for both natural ventilation in summer and heat preservation in winter. 


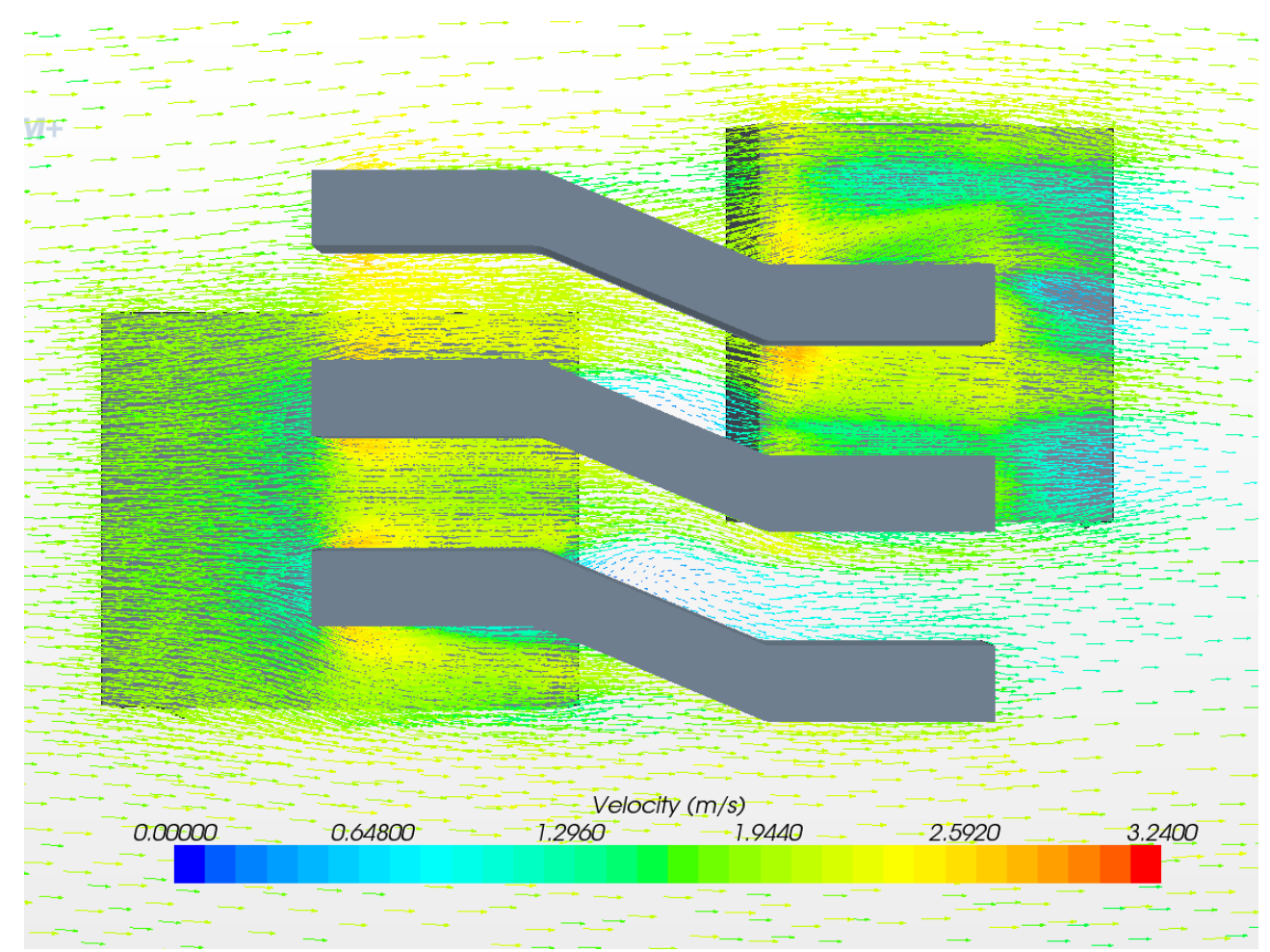

(a) Wind Vector Diagram before Optimization

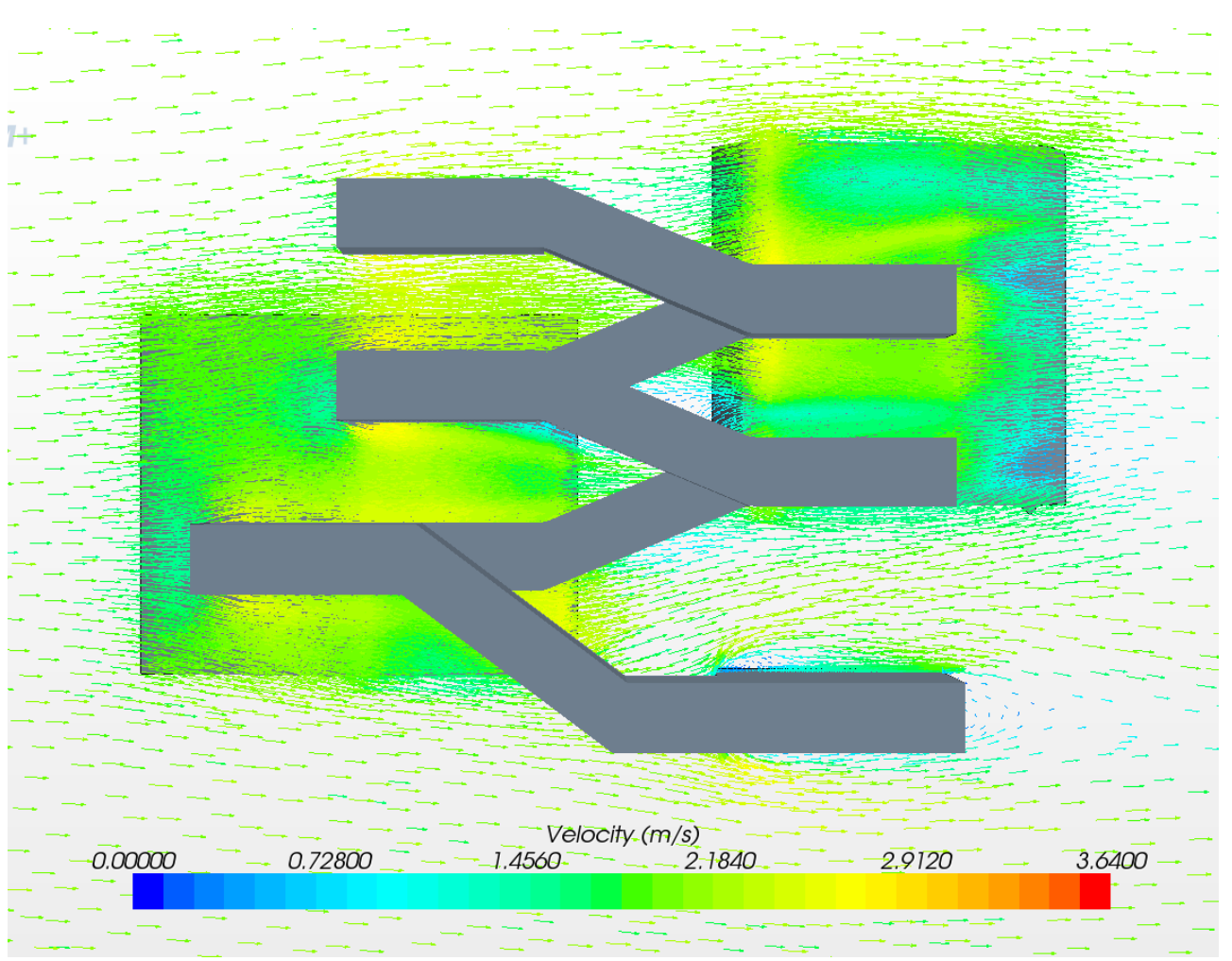

(b) Wind Vector Diagram after Optimization

Figure 3. Optimization of Building Surface 


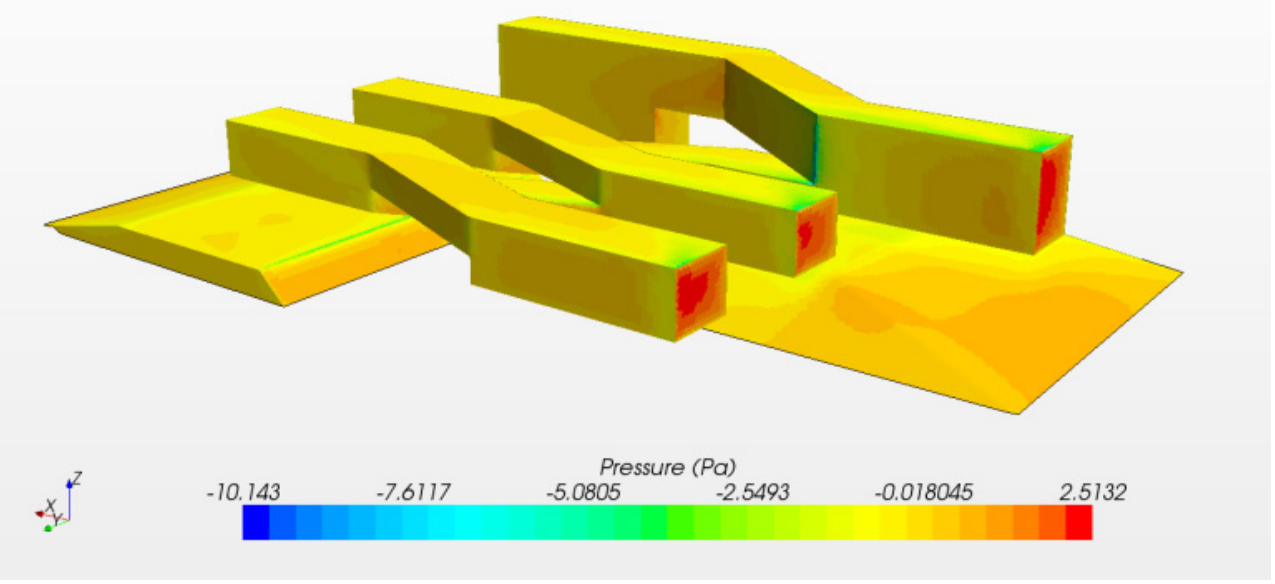

(a)

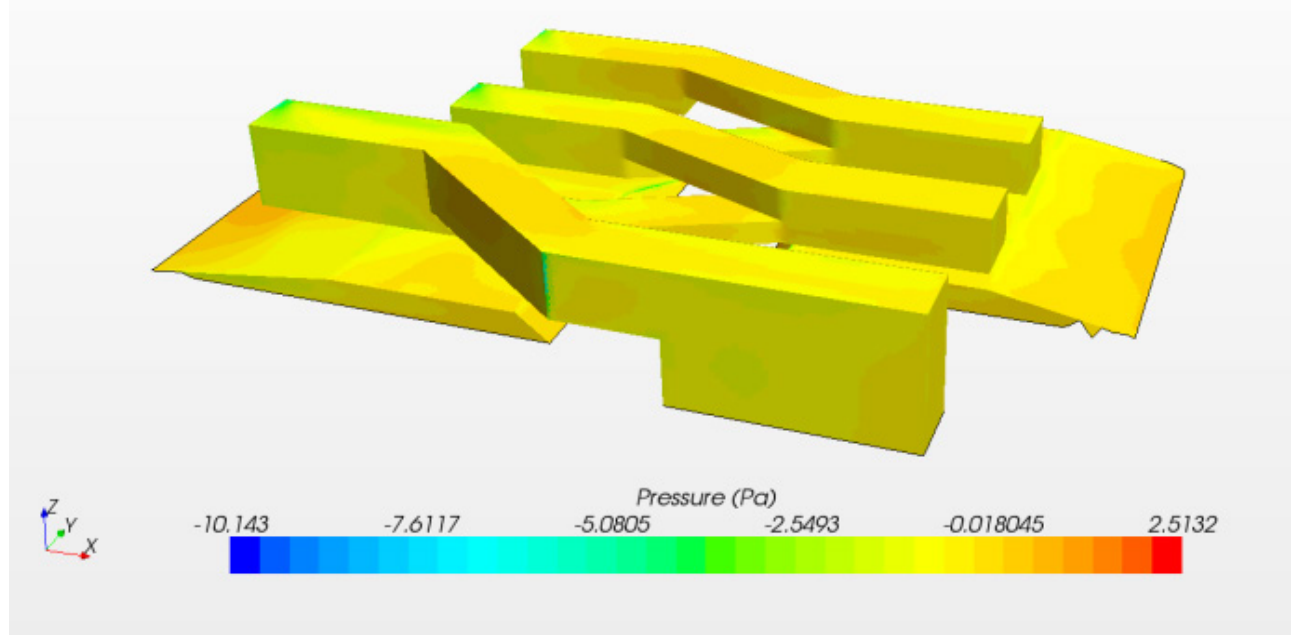

(b)

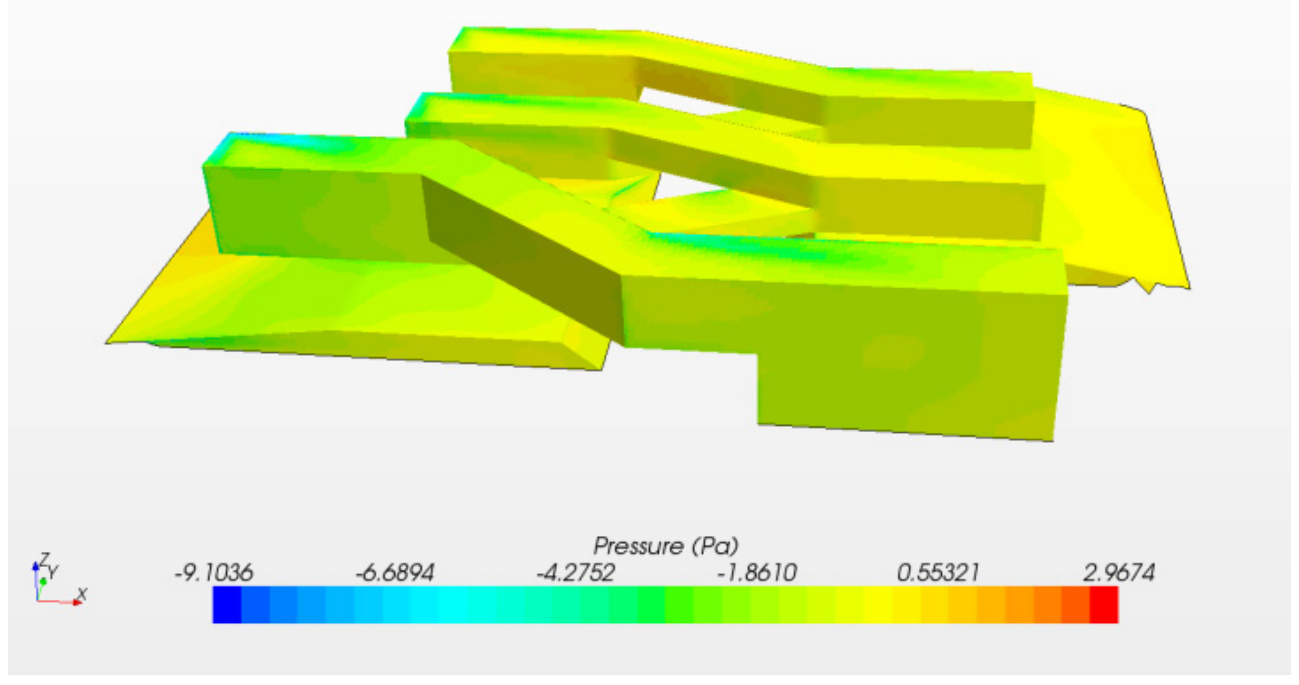




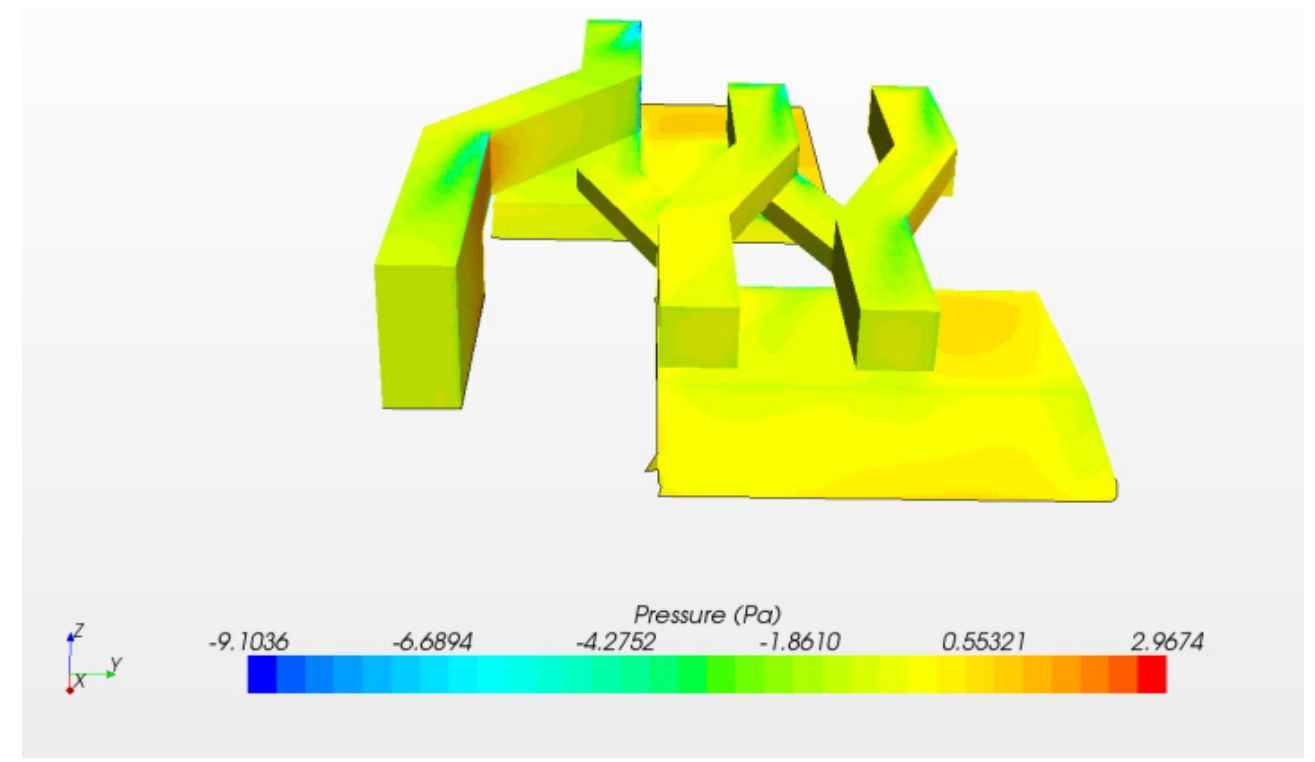

(d)

(a) Pressure distribution diagram on windward side in summer; (b)Pressure distribution diagram on windward side in winter; (c)Pressure distribution diagram on leeward side in summer; (d )Pressure distribution diagram on leeward side in winter;

Figure 4. Pressure Distribution of Windward and Leeward Side of Building in Summer and Winter

\subsubsection{Examination of Surface Pressure}

During the later design process, the zigzag parts between rectangles and squares are opened to below at different height, and the most northern rectangle is raised as a result of consideration for building façade configuration. We use software to simulate and examine the pressure of both the windward side and the leeward side of the building, and the result is shown in Figure 4.

As shown in Figure $4,80 \%$ of the pressure difference between windward and leeward side is over $1.5 \mathrm{~Pa}$, fulfilling the condition for the formation of indoor natural ventilation, which offers basic prerequisite for natural ventilation in summer. The pressure difference on non-windward sides is around $1.2 \mathrm{~Pa}$, which effectively prevents the cold air from infiltrating the building, decreases the energy consumed on heating system, and realizes energy saving for the building.

\subsection{Optimization of Building Skin}

In order to realize natural ventilation for building, in addition to optimizing the pressure difference between windward side and leeward side, the optimization of pressure difference between the air inlet and outlet unneglectable. The material in this design is glass curtain wall, which allows both opening inward and outward. If we choose different opening direction based on different demands for ventilation, and control the wind intensity using shutters, we can then realize the controllability of wind environment.

\section{Summary}

Current paper proposed a design technique that optimizes the building shape through wind environment and based on traditional design. This design technique can combine with the nature the maximum extent possible, respecting designers their concept at the same time, which make the architecture "active" energy saving and improve the micro-climate as a result. In China, designers emphasize how to express their idea through the building shape, lacking of environmental consideration. From an information point of view, this article aims to fill the blank in architectural design caused by deficiency of environmental consideration in 'subjective modeling', successfully finding a balance point between subjective factors and objective factors.

\section{Acknowledgements}

We are very grateful to be sponsored by the National Project of Scientific and Technical Supporting Programs Funded by Ministry of Science \& Technology of China (Grant No. HI T.KISTP.201419).

\section{REFERENCES}

[1] Yusong Han. Generation Based on the architectural form of sunshine and wind environmental impact study [D]. Harbin Institute of Technology, 2013.

[2] Yuanlei. Study on the Wind Simulation-Based Architectural Optimization Design at Conceptual Design Phase [D].Qingdao Technological University, 2013.

[3] Wang J. Strategy of Shenzhen City Riverfront District 
building layout based on wind environment [D]. Harbin Institute of Technology, 2012.

[4] Li B X, Jiang, Zhuang, Liu, Lu\&Wu. Sustainable design method based on outdoor and indoor air environment natural ventilation simulation and optimization of building shape $[\mathrm{J}]$. Green Building, 2014, 04: 56-58.

[5] Qian J. Environmental characteristics of wind around the building at the bottom of the overhead [D].CHONGQING UNIVERSITY, 2010.

[6] C.W. Tsang,K.C.S. Kwok,P.A. Hitchcock. Wind tunnel study of pedestrian level wind environment around tall buildings: Effects of building dimensions, separation and podium [J]. Building and Environment, 2011, 49.
[7] Yafeng Gao,Runming Yao,Baizhan Li,Erdal Turkbeyler, Qing Luo, Alan Short. Field studies on the effect of built forms on urban wind environments [J]. Renewable Energy, 2012,46 .

[8] Li Yang. Green Building Design: Architecture Wind Environment. Shanghai: TongJi University Press,2014.

[9] Fei Chen. Architecture Wind Environment: Summer and cold winter wind climate environmental research and building energy efficiency design. Beijing: China Architecture \& Building Press, 2009.

[10] C.W. Tsang,K.C.S. Kwok,P.A. Hitchcock. Wind tunnel study of pedestrian level wind environment around tall buildings: Effects of building dimensions, separation and podium[J]. Building and Environment,2011,49. 